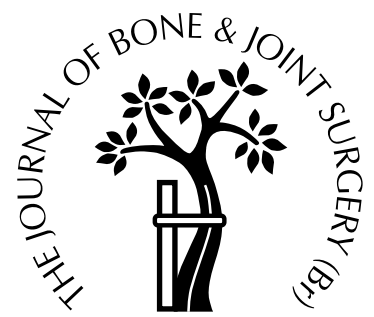

\title{
The influence of weight-bearing on the measurement of polyethylene wear in THA
}

\author{
P. N. Smith, R. S. M. Ling, R. Taylor \\ From the Princess Elizabeth Orthopaedic Centre, Exeter, England
}

W e have studied the influence of weight-bearing on the measurement of wear of the polyethylene acetabular component in total hip arthroplasty using two techniques. The measured vertical wear was significantly greater when radiographs were taken weight-bearing rather than with the patient supine ( $p=0.001, \operatorname{method} 1 ; p=0.007, \operatorname{method} 2)$.

Calculations of rates of linear wear of the acetabular component were significantly underestimated $(\mathbf{p}<0.05)$ when radiographs were taken supine. There are two reasons for this. First, a change in pelvic orientation when bearing weight ensures that the thinnest polyethylene is brought into relief, and secondly, the head of the femoral component assumes the position of maximal displacement along its wear path.

Interpretation of previous studies on both linear and volumetric polyethylene wear in total hip arthroplasty should be reassessed in the light of these findings.

J Bone Joint Surg [Br] 1999;81-B:259-65.

Received 1 June 1998; Accepted after revision 30 September 1998

Wear in the ultra-high polyethylene-bearing surface of an acetabular component is the main cause of late failure of an arthroplasty of the hip. Loosening is attributed to the biological effects of particles of submicron size. ${ }^{1-3}$ Osteolysis is greater in those arthroplasties with a higher level of either linear or volumetric wear of the acetabular component. 4,5

Charnley, Kamangar and Longfield ${ }^{6}$ observed that the pathway of wear of the femoral head through the plastic acetabular component was mainly cylindrical. The direction of wear tended to vary, with some components migrat-

P. N. Smith, BM BS, FRACS Orth, Clinical and Research Fellow R. S. M. Ling, $O B E$, FRCS, Professor

Hip Surgery Unit, Princess Elizabeth Orthopaedic Centre, Barrack Road, Exeter EX2 4UE, UK.

R. Taylor, PhD, Senior Lecturer in Health Services Research Postgraduate Medical School, Barrack Road, Exeter EX2 4UE, UK.

Correspondence should be sent to Mr P. N. Smith at Suite 15, Corinna Chambers, Corinna Street, Phillip ACT 2606, Australia.

C1999 British Editorial Society of Bone and Joint Surgery 0301-620X/99/29154\$2.00

VOL. 81-B, No. 2, MARCH 1999 ing medial to a line projected vertically from the centre of rotation and some lateral to this line. This cylindrical pattern of wear has been confirmed in retrieval studies, 7,8 and forms the basis for quantifying the volume of wear from linear measurement.

The standard method for taking postoperative radiographs is with the patient supine, with the hip bearing no weight. It is assumed that the femoral head will occupy the position of greatest wear along the path of cylindrical wear within the acetabular component and at all times is independent of weight-bearing, and that the thinnest part of the polyethylene component will be above the femoral head. We have studied the influence of weight-bearing on the measurement of polyethylene wear using plain radiographs.

\section{Patients and Methods}

We studied 20 patients (23 arthroplasties of 16 hips) with either known polyethylene wear in a well-performing arthroplasty or with wear obvious in one awaiting revision. Anteroposterior radiographs, centred on the pubis, were taken with the patients lying supine and then when standing bearing weight equally on both legs (Figs 1 and 2). Great care was taken to align the radiographs accurately on the symphysis pubis. The films were then digitised and archived in TGA format on an optical disc for further analysis.

Measurements of wear of the acetabular component were determined using the Orthographics (Salt Lake City, Utah) computer program and corrections made with reference to the known diameter of the femoral head. The images were magnified and enhanced for optimal contrast at the interface between the cement and the acetabular component. The centre of the prosthetic femoral head (CFH) was identified using multiple iterations of known radii to within $0.1 \mathrm{~mm}$. Measurements of wear were made using two differing systems of analysis. In method 1 we used a modification of the technique described by Livermore et al ${ }^{4}$ The distance from the CFH to the interface of the acetabular component and the cement was measured (Fig. 3). The second method followed the system described by Scheier and Sandel $^{9}$ and, later, by Afifi and Jacob. ${ }^{10}$ The equatorial wire marker on the acetabular component was used for reference (Fig. 4). The distance from the midpoint 


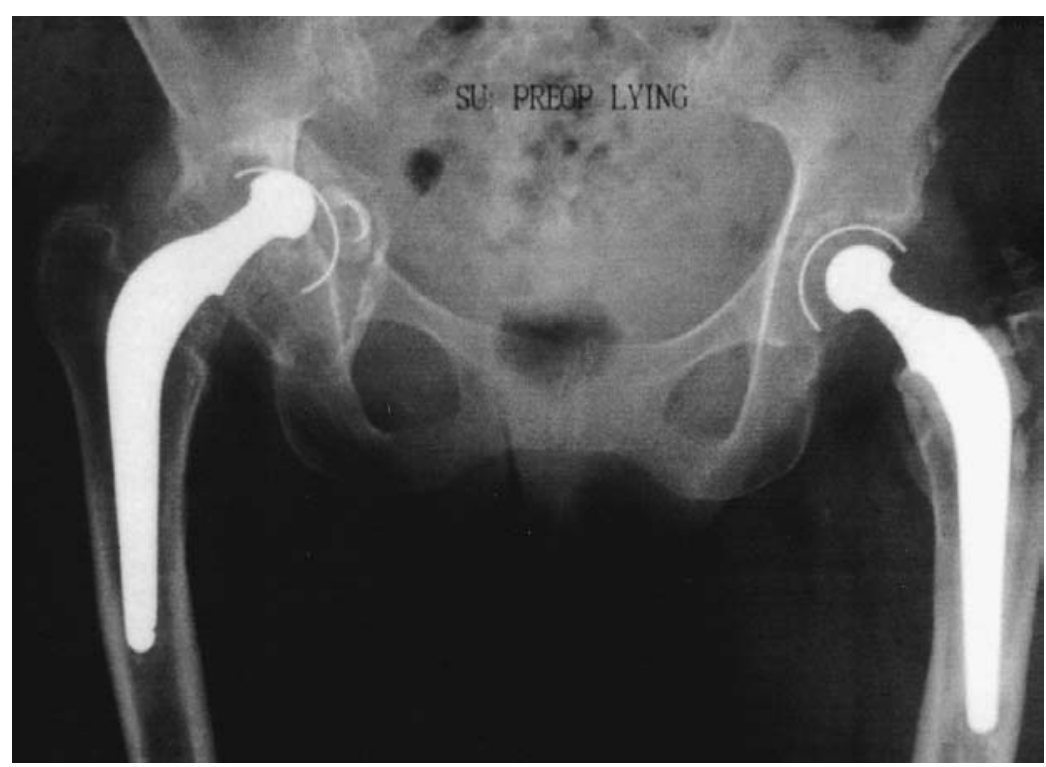

Fig. 1

An AP radiograph taken lying down of the pelvis of a patient who was awaiting revision of a loose right total hip arthroplasty. On the right side an obvious difference is seen in the penetration of the femoral head beyond the wire marker between lying and standing films. Since this cup was loose, it was not included in the analysed group, but the cup on the left side was.

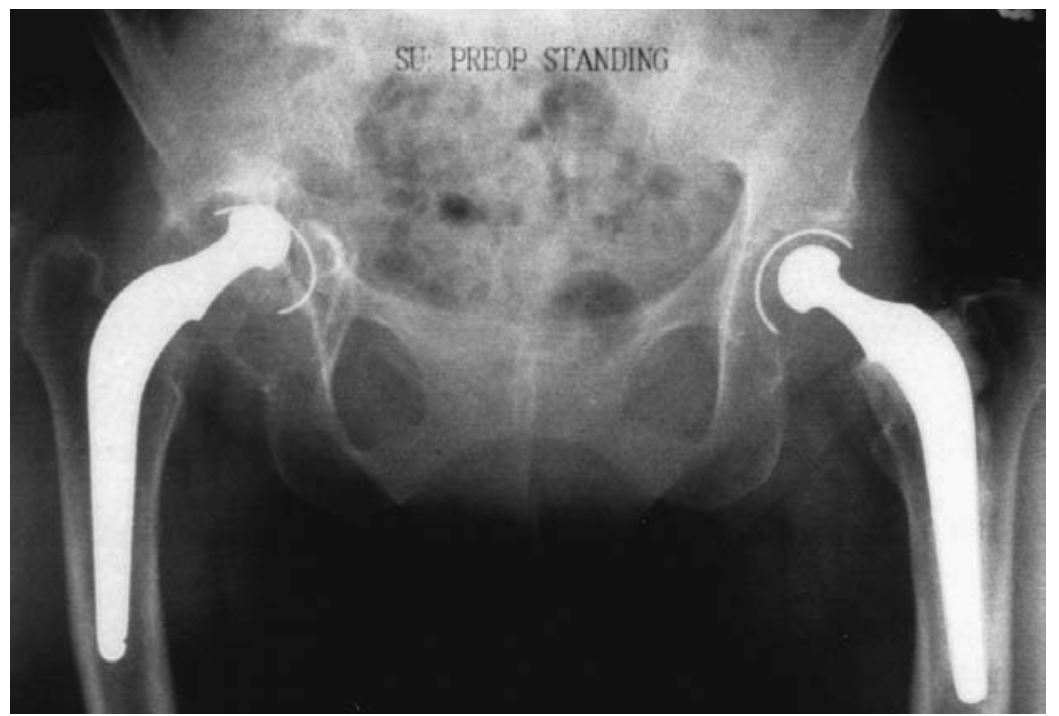

Fig. 2

An AP radiograph of the pelvis of the patient in Figure 1 taken standing. The pelvis has rotated on weightbearing with the sacrum moving distally on standing.

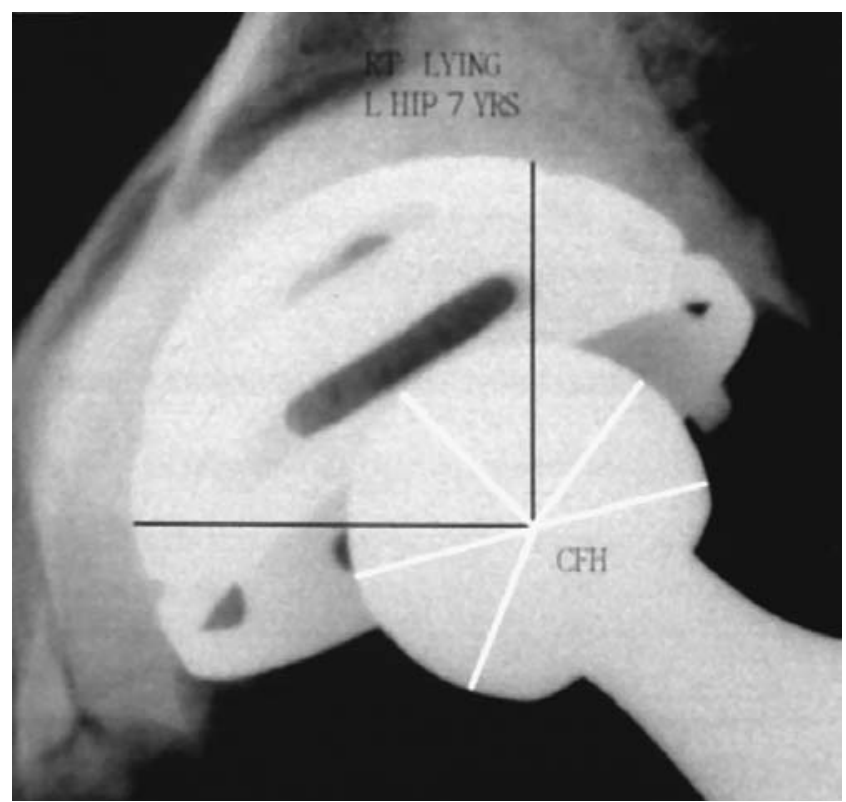

Fig. 3

Radiograph showing an example of method 1. The $\mathrm{CFH}$ is determined using multiple iterations of known radii as shown and the distances to the component-cement interface are measured in the horizontal and vertical planes as indicated. 


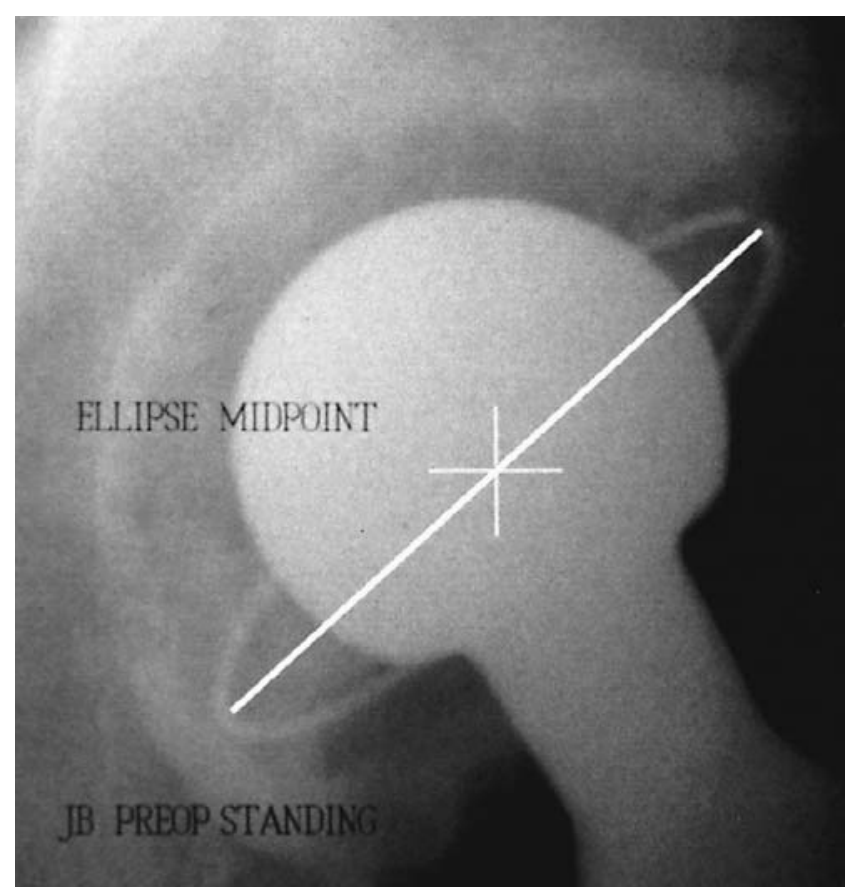

Fig. 4

Radiograph showing an example of method 2. The CFH is determined as shown in Figure 3. The midpoint of the longitudinal axis of the ellipse formed by the wire marker is estimated and the distance between these two points measured in both vertical and horizontal planes.

of the long axis of the elliptical projection of the wire marker to the $\mathrm{CFH}$ was measured in both the horizontal and vertical planes and the average taken of three consecutive readings. Absolute wear, and its direction in the coronal plane, was calculated from these orthogonal measurements, applying the theorem of Pythagoras.

Suitable postoperative radiographs of 12 patients were available to allow dual radiological measurement of wear to be made over the duration of service of the arthroplasty, using current radiographs taken in both lying and standing positions. The immediate postoperative films were all taken with the patient supine, but, comparison of these films, taken before any wear could have occurred, with the latest films taken when lying and standing, is justified.

We used an arbitrary limit to estimate the clinical significance of differences in measured horizontal and vertical linear wear between lying and standing. A difference in either the vertical or horizontal plane of $0.5 \mathrm{~mm}$ or more was held to be significant. A difference of $0.4 \mathrm{~mm}$ was thought to be borderline and of $0.3 \mathrm{~mm}$ or less was not significant. The use of this limit was justified by the high degree of reproducibility and accuracy of this method. Other systems using digitised radiographs have claimed accuracy of within 0.2 to $0.3 \mathrm{~mm}$, significantly better than readings made using manual overlays and reference point detection. ${ }^{11}$ A similar arbitrary limit was used with respect to the calculated total rate of linear wear and the annual rate of wear. Calculation of the latter was thought to be significantly different between lying and standing if the rate differed by as much as $0.05 \mathrm{~mm}$ per year.

We compared measurements of all hips taken in both vertical and horizontal planes when lying and standing. Vertical and horizontal wear and the derived total linear wear were measured using both methods 1 and 2, compared when supine and standing in those hips which had had initial postoperative radiographs, and compared again with the latest films taken lying and standing. Differences were analysed for statistical significance using the paired $t$-test.

\section{Results}

Table I summarises the differences in vertical and horizontal measurements using both methods. The average duration of function of the arthroplasties was 12 years. The prostheses analysed included 14 Exeter, four Charnley and several others. The size of the femoral head varied; four were $22 \mathrm{~mm}$, six $26 \mathrm{~mm}$, one $28 \mathrm{~mm}$, eight $30 \mathrm{~mm}$ and four $32 \mathrm{~mm}$. There were 16 cemented all-polyethylene and seven cemented metal-backed acetabular components in this group.

Using method 1, the modified Livermore technique, there were 11 hips with a difference of $0.5 \mathrm{~mm}$ or more in vertical measurements between radiographs taken with the patient lying and standing. One was borderline with a difference of $0.4 \mathrm{~mm}$ and in the remaining 11 the difference was less than $0.4 \mathrm{~mm}$. In the horizontal plane, there were three hips with a difference of $0.5 \mathrm{~mm}$ or more, four with a borderline difference and 16 had no significant difference. In the only cases in which there was an increased distance of the CFH to the interface in the vertical direction, the maximum difference was $0.2 \mathrm{~mm}$, which was less than half of our projected level of $0.5 \mathrm{~mm}$ for a clinically significant difference. Radiographs taken with the patient standing never gave a value of clinical significant difference less than that when carried out lying. In at least half of the cases there was a value which increased the calculated wear.

An equatorial style wire marker, which could be used to generate a reference point for method 2, was present in 18 hips. The distance in the vertical direction from this point to the $\mathrm{CFH}$ was $0.5 \mathrm{~mm}$ or more in four hips, $0.4 \mathrm{~mm}$ in three and less than $0.4 \mathrm{~mm}$ in the remainder when comparing standing with lying films. In the horizontal direction, there were five hips with $0.5 \mathrm{~mm}$ or greater, three with borderline difference and no significant difference in the remaining hips when comparing standing with lying films. Again, there was no case in which the measurement of linear wear in the vertical direction, using the midpoint of the marker ellipse to the $\mathrm{CFH}$, was reduced by standing. In an appreciable number the distance was significantly greater.

Of the 11 hips with a significantly greater vertical difference between lying and standing, seven had radiographs which were not equivalent in terms of pelvic flexion/ extension. In all seven, the sacrum had moved distally, i.e., caudally, on weight-bearing, leading to pelvic rotation 
Table I. Differences in measured distances using methods 1 and 2 to compare radiographs taken in the lying and standing positions for the 23 patients

\begin{tabular}{|c|c|c|c|c|c|c|}
\hline \multirow[b]{3}{*}{ Hip } & \multirow{3}{*}{$\begin{array}{l}\text { Years in } \\
\text { service }\end{array}$} & \multirow{3}{*}{$\begin{array}{l}\text { Radiograph } \\
\text { parity* }\end{array}$} & \multicolumn{4}{|c|}{ Differences between lying and standing $(\mathrm{mm})$} \\
\hline & & & \multicolumn{2}{|c|}{ Method 1† } & \multicolumn{2}{|c|}{ Method 2\% } \\
\hline & & & Vertical & Horizontal & Vertical & Horizontal \\
\hline 1 & 12 & Flexed & 0.6 & 0.6 & 0.4 & 0.7 \\
\hline 2 & 8 & Equal & -0.1 & 0.1 & 0.1 & 0.2 \\
\hline 3 & 15 & Equal & 0.7 & 0.1 & 0.8 & 0.4 \\
\hline 4 & 21 & Flexed & 0.5 & 0.0 & & \\
\hline 5 & 10 & Equal & 0.5 & -0.1 & 0.7 & 0.0 \\
\hline 6 & 11 & Equal & -0.2 & -0.1 & & \\
\hline 7 & 9 & Equal & -0.1 & -0.4 & 0.1 & -0.5 \\
\hline 8 & 14 & Flexed & 0.2 & -0.1 & 0.4 & 0.4 \\
\hline 9 & 12 & Flexed & 0.5 & 0.0 & & \\
\hline 10 & 9 & Flexed & 0.1 & -0.1 & 0.0 & 0.0 \\
\hline 11 & 15 & Flexed & 0.3 & -0.5 & 0.3 & -0.6 \\
\hline 12 & 12 & Flexed & 0.2 & -0.4 & 0.3 & 0.2 \\
\hline 13 & 7 & Equal & 0.8 & -0.4 & 0.5 & -0.4 \\
\hline 14 & 15 & Equal & 0.7 & -0.4 & 0.5 & -0.6 \\
\hline 15 & 16 & Equal & -0.2 & -0.1 & 0.3 & 0.3 \\
\hline 16 & 9 & Flexed & 1.1 & -0.3 & 0.3 & -0.6 \\
\hline 17 & 11 & Equal & -0.2 & 0.0 & & \\
\hline 18 & 14 & Equal & 0.0 & 0.1 & 0.1 & 0.2 \\
\hline 19 & 12 & Flexed & 1.1 & 0.1 & 0.1 & 0.3 \\
\hline 20 & 22 & Equal & -0.1 & -0.1 & 0.0 & 0.0 \\
\hline 21 & 8 & Flexed & 0.5 & -0.4 & 0.4 & -0.3 \\
\hline 22 & 7 & Flexed & 0.4 & 0.2 & 0.3 & 0.2 \\
\hline 23 & 9 & Flexed & 1.4 & 1.1 & & \\
\hline
\end{tabular}

*parity in terms of pelvic flexion/extension between lying and standing films - 'flexed' means that the pelvis rotates such that the sacrum moves distally with respect to the hips on weight-bearing $\dagger$ method 1: - value, distance CFH to interface increased on WB; method 2: vertical direction, + value, cranial translation of $\mathrm{CFH}$ with respect to midpoint of the long axis of the ellipse; horizontal direction, + value, medial translation of $\mathrm{CFH}$ with respect to midpoint of the long axis of the ellipse

$\ddagger$ only in those cups with a suitable equatorial style wire marker

about the axis of the femoral head (Figs 1 and 2). The other four hips in this group did not have significant alteration in pelvic orientation on weight-bearing. All four of the hips with significantly greater cranial translation of the $\mathrm{CFH}$ with respect to the midpoint of the ellipse had close parity between radiographs taken lying and standing. These four hips were also found to have significant differences in measurements of the distance between the $\mathrm{CFH}$ and the interface.

Measurements using both methods taken in both vertical and horizontal planes were compared when lying and standing using the paired $t$-test. Vertical measurement showed significant differences in both techniques (method $1, p=0.001$, method $2, p=0.007$ ) using the standing films for comparison with lying films, demonstrating greater calculated wear. For horizontal measurement, with method 1 no significant difference was seen when comparing lying with standing. Horizontal measurements revealed a difference $(p=0.15)$ using method 2 , indicating greater calculated wear on radiographs in the standing position compared with those taken lying.

Postoperative radiographs were available for 12 hips for comparison with later lying and standing films. In this group, the total linear wear was calculated using the theorem of Pythagoras and the annual rate of wear generated by dividing total linear wear by years of service of the implant (Table II). For the arbitrary level of $0.05 \mathrm{~mm}$ of annual wear, four hips differed significantly. Three of these four had clinically significant differences in their horizontal and vertical wear and the other was borderline. All of those with a clinically significantly difference in terms of annual wear had total differences in linear wear between lying and standing of at least $0.4 \mathrm{~mm}$, and one hip had a difference of as much as $1.36 \mathrm{~mm}$.

Analysis of a statistically significant difference between wear when determined in the lying and standing positions for these 12 hips was carried out using the paired $t$-test. Using method 1 the vertical, horizontal, derived total linear wear and the annual rate of wear were significantly lower $(p<0.05)$ when measured in the lying position compared with standing. With method 2 a strong trend was evident between lying and standing measurements $(p=0.06$ for vertical and total linear wear and $\mathrm{p}<0.05$ for horizontal wear). With a marginally larger sample size, statistical significance would have been reached using this technique of measurement. 
Table II. Differences in calculated linear wear $(\mathrm{mm})$ and rates of annual wear $(\mathrm{mm} / \mathrm{yr})$ between radiographs taken in the lying and standing positions, for 12 hips in which initial postoperative films were available for comparison with the latest radiographs

\begin{tabular}{|c|c|c|c|c|c|c|c|c|}
\hline \multirow{3}{*}{$\begin{array}{l}\text { Hip } \\
\text { No }\end{array}$} & \multicolumn{4}{|c|}{ Method 1} & \multicolumn{4}{|c|}{ Method 2} \\
\hline & \multicolumn{2}{|c|}{ Total linear wear } & \multicolumn{2}{|c|}{ Wear rate } & \multicolumn{2}{|c|}{ Total linear wear } & \multicolumn{2}{|c|}{ Wear rate } \\
\hline & Lying & Standing & Lying & Standing & Lying & Standing & Lying & Standing \\
\hline 2 & 1.57 & 1.43 & 0.20 & 0.18 & 1.72 & 1.92 & 0.22 & 0.24 \\
\hline $7 *$ & 1.58 & 1.84 & 0.18 & 0.20 & 1.50 & 1.68 & 0.17 & 0.19 \\
\hline 8 & 2.49 & 2.69 & 0.18 & 0.19 & 2.66 & 3.22 & 0.19 & 0.23 \\
\hline $11 \dagger$ & 1.10 & 1.49 & 0.07 & 0.10 & 0.32 & 0.41 & 0.02 & 0.03 \\
\hline $12 *$ & 2.12 & 2.55 & 0.18 & 0.21 & 1.70 & 2.06 & 0.14 & 0.17 \\
\hline $13 \dagger$ & 2.78 & 3.61 & 0.40 & 0.52 & 1.78 & 3.14 & 0.25 & 0.45 \\
\hline 15 & 2.69 & 2.53 & 0.17 & 0.16 & 2.61 & 2.30 & 0.16 & 0.14 \\
\hline $16 \dagger$ & 0.80 & 1.92 & 0.09 & 0.21 & 1.00 & 1.43 & 0.11 & 0.16 \\
\hline 18 & 0.98 & 0.95 & 0.07 & 0.07 & 1.89 & 1.84 & 0.14 & 0.13 \\
\hline 20 & 6.66 & 6.63 & 0.30 & 0.30 & 5.41 & 5.50 & 0.25 & 0.25 \\
\hline $21 \dagger$ & 1.34 & 1.84 & 0.17 & 0.23 & 1.17 & 1.66 & 0.15 & 0.21 \\
\hline $22 *$ & 2.83 & 3.21 & 0.40 & 0.46 & 2.89 & 2.66 & 0.41 & 0.38 \\
\hline
\end{tabular}

* borderline significant clinical difference linear-wear comparing lying with standing

$\dagger$ significant clinical difference for linear-wear comparing lying with standing

\section{Discussion}

Many techniques have been devised to measure the wear of the polyethylene acetabular component in total hip arthroplasty. Charnley and Cupic ${ }^{12}$ used a method based on halving the difference of the width of the narrowest part of the acetabular cup in the weight-bearing area from the width of the polyethylene in the non-weight-bearing area. This study was flawed since it did not take into account the magnification factor of the radiographs. Their method was superseded by that of Charnley and Halley ${ }^{13}$ who compared the thickness of the polyethylene on the immediate postoperative radiograph with that on the latest follow-up film. This method corrected for magnification and had a claimed measurement error of $0.5 \mathrm{~mm}$. The technique allowed the calculation of both the absolute wear and the average rate of wear over time. Both these initial studies utilised the wire marker as the acetabular reference point and this was criticised $^{14}$ because of the variation in orientation of the wire between patients. Griffith et $\mathrm{al}^{15}$ found that the wire would have to be within $10^{\circ}$ of the coronal plane to be used as a reliable marker. They recommended that the cementprosthesis interface should be used as the reference point on the acetabular side.

Livermore et $\mathrm{al}^{4}$ used a modification of the technique of Griffith et $\mathrm{al}^{15}$ whereby the centre of the femoral head was identified using an overlay of concentric circles, and the direction of maximum wear determined with a compass. The wear in this direction was measured using a caliper. They claimed a measurement error of $0.1 \mathrm{~mm}$ with this technique. This method has since been used in a number of studies analysing the wear of the polyethylene component in various total hip replacement systems. ${ }^{16-19}$ Callaghan et $\mathrm{al}^{18}$ augmented this technique using a digitiser to measure the magnitude of wear between the manually identified reference points and claimed an intraobserver and interobserver reliability of within $0.3 \mathrm{~mm}$. Hardinge et $\mathrm{al}^{20}$ have also described the use of a computerised image-manage- ment system to measure migration of components and wear. They claim high reproducibility of within $0.1 \mathrm{~mm}$ and accuracy of within $0.5 \mathrm{~mm}$.

More recently, measurement of the three-dimensional wear of polyethylene using orthogonal plain radiographs has been described by Devane et al. ${ }^{21,22}$ Their method has the advantage over techniques that use a single-plane measurement by including in the wear summation that which has occurred out of the coronal plane. The system has been validated to give a mean accuracy of measurement in any axis of $0.15 \mathrm{~mm}$, with a volumetric accuracy within $0.19 \mathrm{~cm}^{3}$ The error inherent in human identification of the reference points on the femoral head and acetabular components has been addressed by Shaver et al, ${ }^{11}$ who developed a technique in which the edge of the acetabular component is inferred by change in the grey-scale intensity on digitised radiographs. Their method was significantly more accurate and more reproducible than manual measurement with concentric circular overlays. The technique utilised in our study is equally accurate. Error inherent in measurement was minimised by using a single observer to avoid interobserver bias, and by taking the average of three separate measurements of migration of the head for each radiograph.

Our results show that using two methods of measurement there is a difference between weight-bearing (standing) and non-weight-bearing (lying) which is statistically significant. Using generous limits for the clinical significance of difference of $0.5 \mathrm{~mm}$ or more in linear wear in either horizontal or vertical planes, a large fraction of our sample group had significant alterations in linear wear when comparing standing and lying using either method. Most importantly, none had significant wear which was reduced when standing compared with lying. Similarly, using a wide margin of significance for total calculated linear wear and annual rate of wear, a significant increase was found in a high proportion of our patients. Again no hip had significantly reduced calculated total linear wear or annual rate of wear when standing compared with lying. Radiographs taken standing 
showed either no difference or more measured wear than those taken lying.

The differences seen between standing and lying are due to two factors. First, the pathway of wear is essentially cylindrical. Therefore, with the patient supine the femoral head should lie at the point of maximal wear. This may be true for most hips but it is clearly not the case for all. Examples are seen in the four hips in which the radiographs taken lying and standing are closely correlated in terms of pelvic rotation but show a significant difference in wear using both methods of evaluation. Secondly, the pelvis changes position between lying and standing. When standing the mass of the body lies posterior to the hips and the pelvis rotates, with the sacrum moving distally with respect to the hips. The major wear on an acetabular component occurs when upright, and therefore the thinnest polyethylene is above the femoral head. It is appropriate to measure in this position. When the patient lies supine, the pelvis derotates with the sacrum moving cranially with respect to the hips, and in so doing moves a slightly thicker part of the polyethylene above the femoral head. This effect would be magnified by greater wear of the acetabular component. Seven hips had standing radiographs which, although well centred with respect to the lying films, had a significant change in pelvic flexion and a significant difference in wear compared with the measurements taken lying.

The possible effect of elastic deformation was considered in a separate group of ten total hip arthroplasties which were assessed for wear by comparing radiographs taken in the lying and standing positions at one year after operation. No statistical or clinical differences were found in this group. As minimal wear was expected in these hips, and no differences in measured wear were found between lying and standing, we conclude that creep, if it does occur, is so small as not to be measurable.

The question of which method gives the most accurate measurement of wear was addressed by Wroblewski ${ }^{8}$ who noted a high correlation between his radiological measurements and shadowgraphs of retrieved components. Livermore et al $^{4}$ similarly noted agreement between their technique and wear analysed by sectioning retrieved specimens, although the actual measurements were not given in detail. A similar correlation was noted for their method by Afifi and Jacob, ${ }^{10}$ who examined three retrieved components. Ilchmann ${ }^{23}$ found differences in estimation of wear between the Livermore method and the method of Scheier and Sandel when compared with an RSA technique. Their study did not include any retrieved material and therefore definitive conclusions as to the optimal method of measurement are not available. The two methods used in our study have shown a high level of agreement in the detection and quantification of wear in the acetabular component. The absolute numbers differ to a small degree which may be due to a number of factors, such as identification and location of reference points. The effect of pelvic rotation in bringing thicker polyethylene above the femoral head in the supine position, will be seen more in the technique in which the superior component-cement interface is used for reference than in that using the elliptical projection of the equatorial marker.

Kabo et $\mathrm{al}^{24}$ found that the actual wear of retrieved acetabular components, shown using a shadowgraph method, was underestimated using radiological techniques. This phenomenon was also noted in a study by Ohlin and Selvik, ${ }^{25}$ in which the actual wear was measured using a highly precise co-ordinate measuring machine. The observation that not all wear occurs in the purely coronal plane when supine films are used for analysis provides at least part of the explanation for this discrepancy. Wroblewski ${ }^{8}$ noted that nine of 23 sockets analysed wore in a direction anterior to the coronal plane. This is consistent with our observation that the pelvis is rotated in the supine position, therefore moving the wear path from the truly vertical plane. Wear out of plane has been considered in detail by Devane et $\mathrm{al}^{21,22,26}$ in the development and application of a technique for volumetric three-dimensional wear of the acetabular component. An explanation for the variance between measured and actual wear is that the radiographs are not taken in the weight-bearing position, and therefore the position of maximal wear is not measured.

We have shown clinically relevant and highly statistically significant differences in the linear wear of the polyethylene acetabular component by comparing radiographs taken standing and lying. These differences are thought to be due to a combination of two factors. The femoral head does not always occupy the point of maximal wear along the cylindrical wear path in the polyethylene cup, and pelvic rotation in the supine position moves a greater thickness of polyethylene into silhouette superior to the prosthetic femoral head. This may also have the spurious effect of creating an apparently eccentric wear path. In future, monitoring the wear of acetabular components using sequential radiological examination should take this into account.

One or more of the authors have received or will receive benefits for personal or professional use from a commercial party related directly or indirectly to the subject of this article. In addition benefits have also been or will be directed to a research fund, foundation, educational institution, or other non-profit institution with which one or more of the authors is associated.

\section{References}

1. Howie DW. Tissue response in relation to type of wear particles around failed hip arthroplasties. J Arthroplasty 1990;5:337-48.

2. Amstutz HC, Campbell P, Kossovsky N, Clarke IC. Mechanism and clinical significance of wear debris induced osteolysis. Clin Orthop 1992;276:7-18.

3. Schmlzried TP, Jasty M, Harris WH. Periprosthetic bone loss in total hip arthroplasty: polyethylene wear debris and the concept of effective joint space. J Bone Joint Surg [Am] 1992;74-A:849-63.

4. Livermore J, Ilstrup D, Morrey B. Effect of femoral head size on wear of the polyethylene acetabular component. J Bone Joint Surg [Am] 1990;72-A:518-28.

5. Schmalzreid TP, Guttman D, Grecula M, Amstutz HC. The relationship between design, position and articular wear of acetabular components inserted without cement and the development of osteolysis. J Bone Joint Surg [Am] 1994;76-A:677-88.

6. Charnley J, Kamangar A, Longfield MD. The optimum size of prosthetic heads in relation to the wear of plastic sockets in total replacement of the hip. Med Biol Engin 1969;7:31-9. 
7. Dowling JM, Atkinson JR, Dowson D, Charnley J. The characteristics of acetabular cups worn in the human body. J Bone Joint Surg [Br] 1978;60-B:375-82.

8. Wroblewski BM. Direction and rate of socket wear in Charnley lowfriction arthroplasty. J Bone Joint Surg [Br] 1985;67-B:757-61.

9. Scheier H, Sandel J. Wear affecting the plastic cup in metal-plastic endoprostheses. In: Gschwend N, Debrunner HU, eds. Total hip prosthesis. Bern: Hans Huber, 1976:186-90.

10. Afifi KF, Jacob HA. Wear measurements of hip prostheses with UHMW polyethylene (RCH 1000) socket and chromium plated protasul-19 head. Z Orthop 1981;119:157-62.

11. Shaver SM, Brown TD, Hillis SL, Callaghan JJ. Digital edgedetection measurement of polyethylene wear after total hip arthroplasty. J Bone Joint Surg [Am] 1997;79-A:690-700.

12. Charnley J, Cupic Z. The nine and ten year results of the low-friction arthroplasty of the hip. Clin Orthop 1973;95:9-25.

13. Charnley J, Halley DK. Rate of wear in total hip replacement. Clin Orthop 1975;112:170-9.

14. Clarke IC, Black K, Rennie C, Amstutz HC. Can wear in total hip arthroplasties be assessed from radiographs? Clin Orthop 1976;121: $126-42$.

15. Griffith MJ, Seidenstein MK, Williams D, Charnley J. Socket wear in Charnley low friction arthroplasty of the hip. Clin Orthop 1978; 137:37-47.

16. Bankston AB, Ritter MA, Keating EM, Faris PM. Measurement of polyethylene thickness in total hip arthroplasty. J Arthroplasty 1994; 9:533-8.
17. Bankston AB, Keating EM, Ranawat CS, Faris PM, Ritter MA. Comparison of polyethylene wear in machined versus moulded polyethylene. Clin Orthop 1995;317:37-43.

18. Callaghan JJ, Pedersen DR, Olejniczak JP, Goetz DD, Johnston RC. Radiographic measurement of wear in 5 cohorts of patients observed for 5 to 22 years. Clin Orthop 1995;317:14-8.

19. Bankston AB, Cates H, Ritter MA, Keating EM, Faris PM. Polyethylene wear in total hip arthroplasty. Clin Orthop 1995;317:7-13.

20. Hardinge K, Porter ML, Jones PR, Hukins DWL, Taylor CJ. Measurement of total hip prostheses using image analysis: the MAXIMA hip technique. J Bone Joint Surg [Br] 1991;73-B:724-8.

21. Devane PA, Bourne RB, Rorabeck CH, Hardie RM, Horne JG. Measurement of polyethylene wear in metal-backed acetabular cups. Clin Orthop 1995;319:303-16.

22. Devane PA, Bourne RB, Rorabeck CH, MacDonald S, Robinson EJ. Measurement of polyethylene wear in metal backed acetabular cups. 2. Clinical Application. Clin Orthop 1995;319:317-26.

23. Ilchmann T. Radiographic assessment of cup migration and wear after hip replacement. Acta Orthop Scand 1997;276:1-26.

24. Kabo JM, Gebhard JS, Loren G, Amstutz H. In vivo wear of polyethylene acetabular components. J Bone Joint Surg [Br] 1993; 75-B:254-8.

25. Ohlin A, Selvik G. Socket wear assessment: a comparison of three different radiographic methods. J Arthroplasty 1993;8:427-31.

26. Devane PA, Robinson EJ, Bourne RB, et al. Measurement of polyethylene wear in acetabular components inserted with and without cement: a randomised trial. J Bone Joint Surg [Am] 1997;79-A: $682-9$ 